\title{
INFLUENCE OF VACUUM ON ADJUSTING PARAMETERS OF HIGH PRESSURE DIE CASTING PARTS FROM ALLOY AISi9Cu3(Fe)
}

\author{
${ }^{1}$ Maciej FERDYN, ${ }^{2}$ Jarosław PIĄTKOWSKI \\ ${ }_{1}$ Private person, Katowice, Poland, EU, maciej.ferdyn@gmail.com \\ ${ }^{2}$ Silesian University of Technology, Department of Materials Technology, Katowice, Poland, EU, \\ jaroslaw.piatkowski@polsl.pl
}

https://doi.org/10.37904/metal.2020.3630

\begin{abstract}
In paper authors present the influence of adjusting key parameter, which is changeover point between first and second phase, on quality of casting from AISi9Cu3(Fe) alloy. Technological tests were carried out in industrial conditions on a machine with a clamping force of $1200 \mathrm{Mg}$ with variable parameters of the piston operation. Production practice has shown that with inappropriate selection of parameters, on the final products significant casting defects appear in the form of: drags, delaminations, sticking of castings on the mould and discoloration associated with uneven filling of the mould cavity. Based on the temperature distribution of the mould, the spray head was checked for correct operation and its impact on defects was eliminated. The filling of the mould was checked at the time of switching the second phase with the vacuum turned on and off in the mould cavity. It was shown that the key parameter is the appropriate selection of the changeover point of the second phase which is influenced by the vacuum in the cavity of closed mould.
\end{abstract}

Keywords: High pressure die casting, aluminum alloys, process parameters

\section{INTRODUCTION}

High pressure die casting is a process that is characterized by very high speed and pressure not found in other foundry technologies. Currently the most common in production of aluminum casting companies are coldchamber machines to which liquid metal is supplied manually or automatically. The injection process is part of the casting cycle, which can be divided into three phases. The first phase (the slowest) leading the metal to the in-gate. The second phase (the fastest) feeding of the metal to the mould cavity and the third phase refining of the metal in the mould under high pressure. The selection of appropriate process parameters is a key to obtaining qualitatively appropriate castings [1]. In the era of increasing requirements for castings, it is necessary to use a vacuum to eliminate air from the mould cavity before injection. This has a significant impact on the selection of casting parameters, and in particular on the selection of changeover point between first and second phase. The work focuses on the elimination of casting defects by appropriate selection of the casting parameter which is the selection of the second phase changeover poing. The spraying process was checked first to eliminate its impact on the occurrence of defects. The castings were made of AISi9Cu3(Fe) - ENAC 46000 alloy.

The aim of the research was to assess the impact of vacuum on the selection of technological parameters of the high pressure die casting process for automotive components. The correct value of the vacuum in the working chamber of the casting machine will also help to improve the material quality in terms of reducing the defects of finished products. 
Table 1 Composition of alloy EN AC 46000 in wt\% according to the PN-EN 1706: 2011 [2]

\begin{tabular}{|c|c|c|c|c|c|c|c|c|c|c|c|c|}
\hline Range & Al & $\mathrm{Si}$ & $\mathrm{Fe}$ & $\mathrm{Cu}$ & $M n$ & $\mathrm{Mg}$ & $\mathrm{Cr}$ & $\mathrm{Ni}$ & $\mathrm{Zn}$ & $\mathrm{Pb}$ & Sn & $\mathrm{Ti}$ \\
\hline Min. & \multirow{2}{*}{ Residue } & 8 & 0.6 & 2 & 0 & 0.15 & & & & & & \\
\hline Max. & & 11 & 1.1 & 4 & 0.55 & 0.55 & 0.15 & 0.3 & 1.2 & 0.35 & 0.035 & 0.2 \\
\hline
\end{tabular}

\section{HIGH PRESSURE DIE CASTING PROCESS}

The high pressure casting process in a cold chamber machine can be divided into 9 basic stages shown in the diagram below Figure 1:
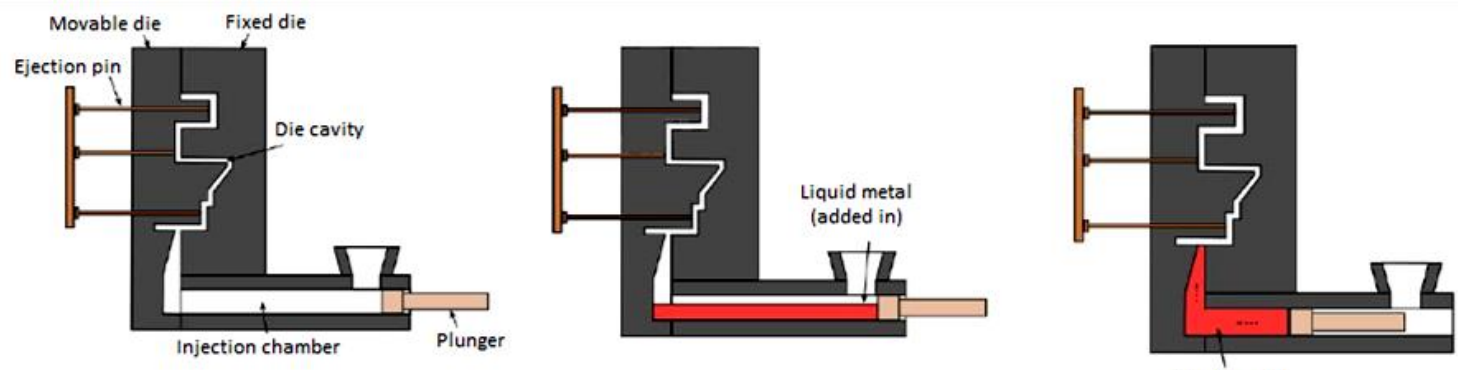

Step 1 (cycle start)

Die closed and locked

- Plunger withdrawn

Step 2

Step 3

Liquid metal

- Ejection pins withdrawn

- Liquid metal added in the injection chamber

- Plunger slowly pushes the liquid

into the sprue until reaching the

in-gate
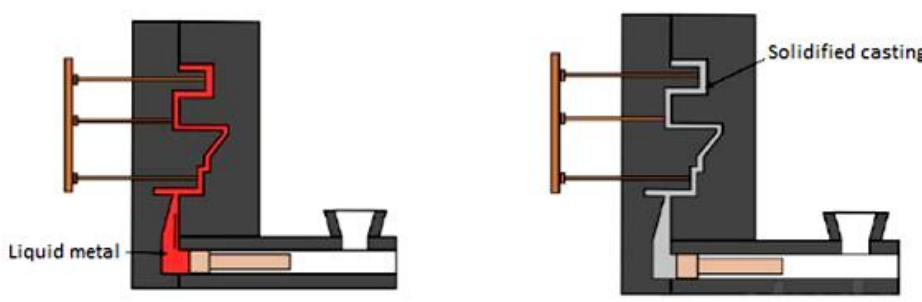

Step 4

- Plunger moves quickly to shoot the liquid into the die cavity under high pressure

Step 5

- Liquid metal solidifies to form the casting

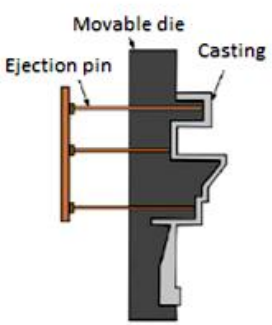

Step 6

- Movable die opens together with the ejection pins - Casting attached to the movable die

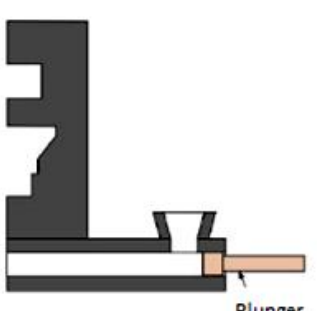

Plunger 


\section{INFLUENCE OF VACCUM ON PROCESS PARAMETERS}

During casting on the initial parameters of the valve cover casting defects appeared which are presented in Figures 2-4.

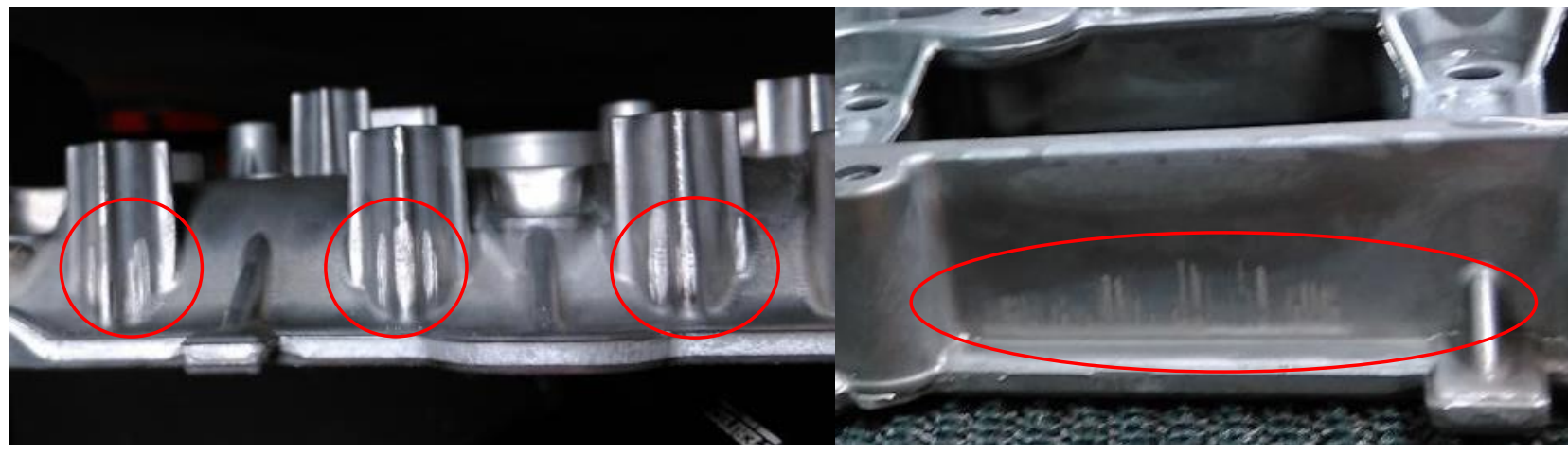

Figure 2 Drags on the part at the gating system

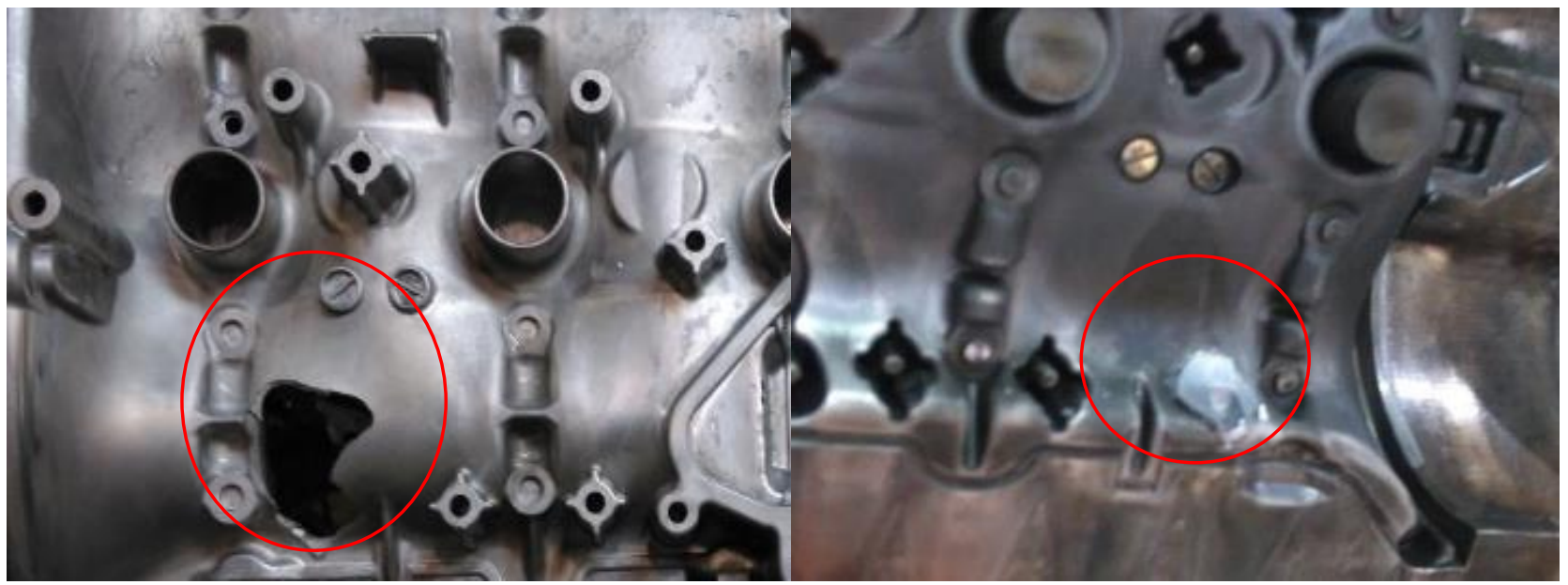

Figure 3 Casting sticks to the fixed die

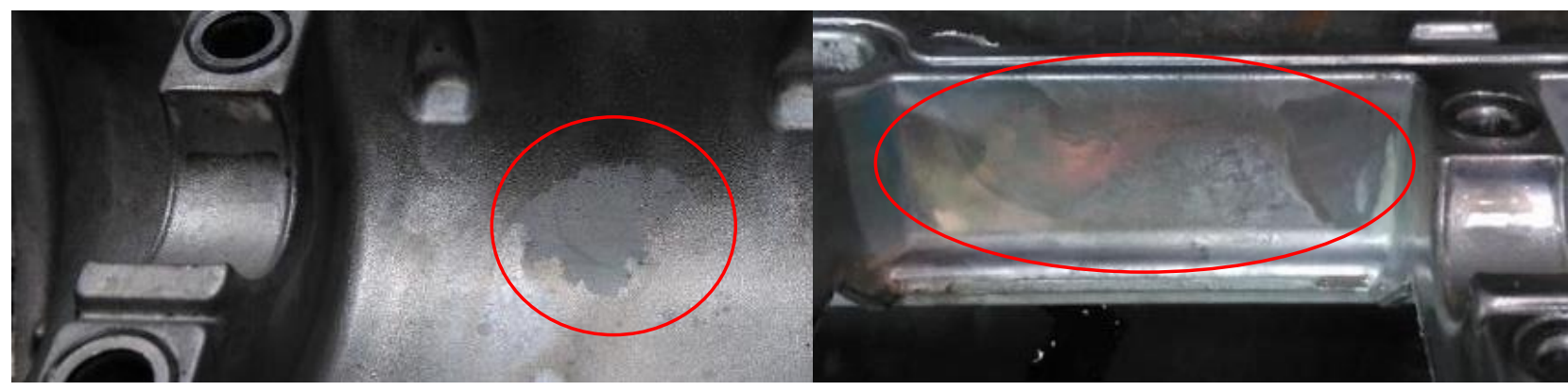

Figure 4 Visible traces of metal joining and delamination

In order to eliminate defects, the efficiency of the spraying system was checked first. By observing mould temperatures in the production cycle, no deviations from production practice were observed. Irregularities of the spraying system were thus excluded. The next step was to carry out the mould filling test with / without vacuum. An important parameter affecting the process is the piston speed, all speeds were constant during casting [4]. The liquid metal should be at the height of in-gate to obtain the required quality of castings. 


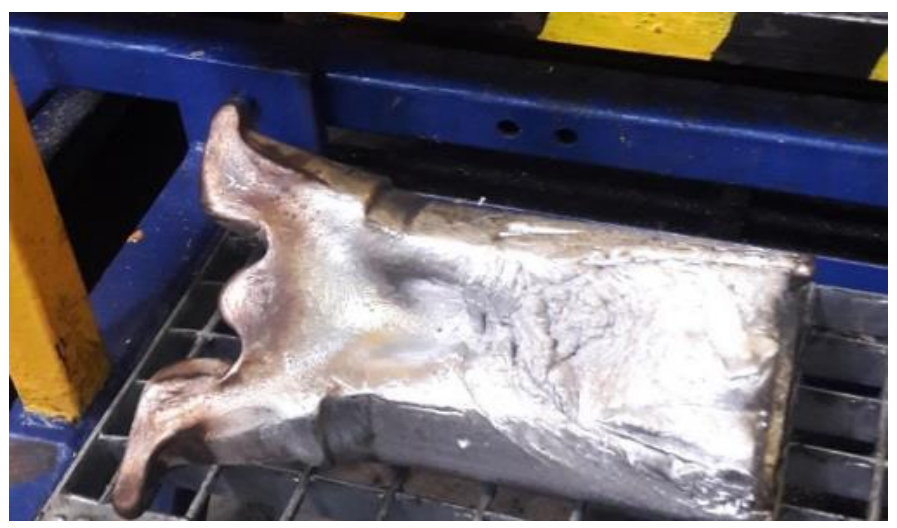

Figure 6 Mould filling test without vacuum, changeover point $450 \mathrm{~mm}$

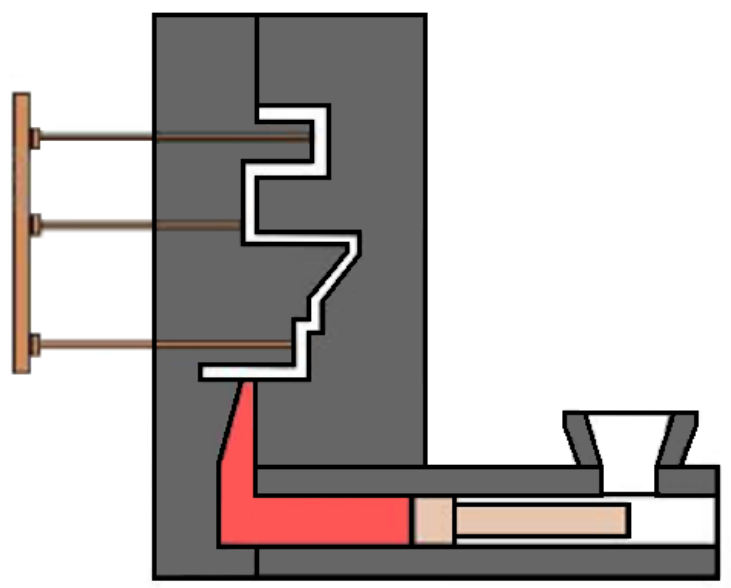

Figure 7 Mould filling test without vacuum, changeover point $500 \mathrm{~mm}$

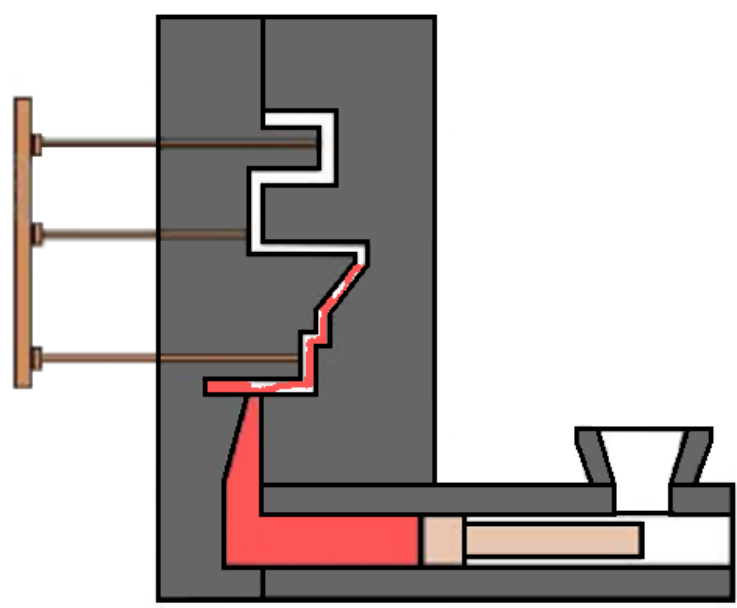

Figure 8 Mould filling test with vacuum, changeover point $500 \mathrm{~mm}$

The results of the fill test are shown in Figures 6-8. For reasons of technological secrecy, the results are shown in the diagrams. If the vacuum was not used, the appropriate switching point would be $500 \mathrm{~mm}$, however, the effect of vacuum below 100 mbar causes metal to be drawn into the mould cavity (prefill) before switching the second phase. Figure 8. The final parameter of the switching point was $475 \mathrm{~mm}$, which compensated for the impact of the vacuum on filling the cavity forms and gating system. 


\section{CONCLUSION}

The selection of casting parameters is key to obtaining quality castings. Among the machine parameters multiplied pressure in the third phase, Plunger velocity in the second phase, die cavity filling time have significant effect on porosity formation in aluminum die castings which directly responds to mechanical properties of castings. In paper parameter changeover point of second phase was investigated.

Initial parameters resulting from theoretical calculations are an indication for the proper conduct of the process and test castings should be carried out to match the parameters to both the mould and the type of casting machine. As shown in the article, the type of pressure casting process (conventional or vacuum) has a significant impact.

\section{ACKNOWLEDGEMENTS}

This article is the result of research related to the program of the Polish Ministry of Science and Higher Education titled implementation doctorate.

\section{REFERENCES}

[1] CHOI, S., KIM, Y., CHO, J., KANG, C. Influence of die casting process parameters on castability and properties of thin walled aluminum housings. International Journal of Cast Metals Research. 2008, vol. 21, pp. 330-333.

[2] PN-EN 1706: Aluminum i stopy aluminum - Odlewy - Skład chemiczny i własności mechaniczne (Aluminum and aluminum alloys - Castings - Chemical composition and mechanical properties). 2011.

[3] DUDEK, Piotr. Modern high-pressure die casting technologies for structural castings. 2017.

[4] PAŁYGA, Ł. STACHOWICZ, MATEUSZ. GRANAT, K. Effect of selected parameters of pressure die casting on quality of AISi9Cu3 castings. Archives of Foundry Engineering. 2015, vol. 15, pp. 85-90. 10.1515/afe-2015-0044. 